\title{
Resíduo líquido de laticínio como fertilizante para o capim Mombaça
}

\author{
Perlon Maia Santos*, José Expedito Cavalcante Silva, Antonio Clementino Santos, \\ Jose Geraldo Donozetti Santos, Aridouglas Santos Araújo, Marcos Odilon Dias Rodrigues
}

\section{Resumo}

A fertilização química ou orgânica pode ser um dos fatores responsáveis pela sustentabilidade das pastagens abrindo espaço, desta forma, para o uso de subprodutos da agroindústria. Objetivou-se determinar o efeito da aplicação de resíduo de laticínio nas características agronômicas do capim Mombaça para verificar o potencial de fornecimento de fósforo (P) e potássio (K). Seis doses de resíduo líquido de laticínio correspondente a 10, 50, 100, 150, 200 e $400 \mathrm{~m}^{3} \mathrm{ha}^{-1}$ foram avaliadas em quatro ciclos produtivos, determinando-se os acúmulos de massa seca de forragem, de lâminas foliares, de colmos, de material morto, o índice de área foliar, o número de perfilhos basais, a relação folha/colmo e a altura das plantas. Observou-se que o aumento das doses promoveu aumento do desempenho da gramínea. A aplicação de $400 \mathrm{~m}^{3} \mathrm{ha}^{-1}$ garante produções similares àquela com adubação química de $\mathrm{P}$ e $\mathrm{K}$, substituindo $25 \%$ da adubação fosfatada e $100 \%$ da adubação potássica. O resíduo líquido de laticínio é bom fornecedor de potássio à gramínea forrageira capim Mombaça e apresenta efeito residual positivo sobre o acúmulo de forragem.

Palavras chave: adubação orgânica, produção de forragem, resíduo de agroindústria

\section{Liquid dairy waste as fertilizer for 'Mombaça' grass}

\begin{abstract}
The chemical or organic fertilizer can be responsible for the sustainability of pastures, with an alternative of application for the agro-industry subproducts. This study aimed to evaluate the influence of dairy waste application on Mombaça grass agronomic characteristics to verify the potential supply of phosphorus (P) and potassium (K). Six doses of liquid dairy waste corresponding to 10,50,100, 150, 200 and $400 \mathrm{~m}^{3} \mathrm{ha}^{-1}$ were evaluated in four production cycles. The accumulation of dry forage, leaf blade, stem, dead material, leaf area index, number of tillers, leaf/stem and plant height were evaluated. Increasing levels resulted in the increase of the grass performance. The application of $400 \mathrm{~m}^{3} \mathrm{ha}^{-1}$ of liquid dairy waste ensures similar productions when compared to the application of $\mathrm{P}$ and $\mathrm{K}$ through chemical fertilizers, replacing $25 \%$ of the phosphorus and $100 \%$ of potassium fertilization. The liquid dairy waste can be used as a potassium supplier to Mombaça grass and have a positive residual effect on biomass accumulation.
\end{abstract}

Key words: organic fertilization, grass production, agro-residue. 


\section{Introdução}

Brasil tem produzido em média $21 \times 10^{9}$ $\mathrm{L}$ de leite/ano, gerando concomitantemente $94 \times 10^{9} \mathrm{~L}$ de efluentes, que sofrem restrições quanto a seu lançamento no ambiente (Cammarota \& Freire, 2006). No entanto, a matéria orgânica e os minerais destas águas abrem espaço a uma gama de tecnologias a serem utilizadas.

A matéria orgânica do solo é entendida como quantificador de sua qualidade, mas os processos de formação e manejo das pastagens normalmente causam a redução do carbono no solo (Collier et al., 2008). Logo, a aplicação de compostos orgânicos pode ser de fundamental importância na manutenção das características físicas, químicas e bioquímicas do solo e na manutenção da produtividade das pastagens ao longo do tempo.

Segundo Öborn et al. (2005), a deposição de efluentes em solos sob cobertura vegetal perene, como pastagens, aumenta a restituição e ciclagem dos nutrientes. O íon $\mathrm{K}^{+}$está presente em grande concentração no efluente de laticínio devido à utilização do $\mathrm{KOH}$ nos procedimentos de limpeza, além da fração $\mathrm{N}, \mathrm{P}$ e K+ contida nos resíduos do leite (Tisdale et al., 1999).

Embora os resíduos da agroindústria forneçam nutrientes, sua aplicação contínua pode favorecer a geração de ambientes anaeróbios próximos às raízes das plantas em função da degradação da matéria orgânica e elevar demasiadamente os teores de lodo, P e
$\mathrm{K}^{+}$do solo, já que estes resíduos podem conter elevadas concentrações destes elementos (McDowell \& Koopmans, 2006). Logo, a adoção de tecnologias de reaproveitamento deve ser criteriosamente mensurada para a verificação de seu potencial sobre a resposta agronômica da planta.

Este estudo teve por finalidade verificar o potencial de uso de águas residuais da indústria de laticínios em plantas de capim Mombaça (Panicum maximum Jack. cv. Mombaça). Avaliar o impacto da aplicação direta do resíduo nas características agronômicas da planta forrageira e verificar o efeito residual para a gramínea, constatando o potencial de fornecimento de $P$ e $\mathrm{K}^{+}$.

\section{Material e Métodos}

O estudo foi realizado na Escola de Medicina Veterinária e Zootecnia (EMVZ), da Universidade Federal do Tocantins (UFT), no período de 12/2009 a 5/2010 (Tabela 1), município de Araguaína, TO. A região é classificada como ecótono Cerrado e Floresta Amazônica, com clima do tipo Aw (quente e úmido), de acordo com Köppen (1938), com chuvas de outubro a abril, precipitação anual média de $1.863 \mathrm{~mm}$, altitude média de $240 \mathrm{~m}$ e umidade do ar com média de $78 \%$. Os dados climáticos referentes ao período experimental foram coletados na estação meteorológica do Instituto Nacional de Meteorologia localizada no campus da EMVZUFT (Tabela 1).

Tabela 1. Temperatura, umidade e precipitação pluvial durante o período experimental no ano de 2010 e média histórica dos últimos 10 anos

\begin{tabular}{|c|c|c|c|c|c|c|c|}
\hline \multirow{2}{*}{ Mês } & \multicolumn{3}{|c|}{ Temperatura média do ar $\left({ }^{\circ} \mathrm{C}\right)$} & \multirow{2}{*}{$\frac{\text { Umidade }}{(\%)}$} & \multirow{2}{*}{$\frac{\text { Precipitação }}{\text { (mm) }}$} & \multirow{2}{*}{ Ciclos } & \multirow[t]{2}{*}{ Datas dos ciclos } \\
\hline & Máxima & Mínima & Média & & & & \\
\hline JAN & 30,50 & 21,60 & 25,04 & 85 & 216,7 & & \\
\hline FEV & 30,70 & 21,30 & 25,90 & 86 & 231,8 & $1^{\circ}$ & $01 / 02$ a 29/02 de 2010 \\
\hline MAR & 30,40 & 21,50 & 26,30 & 86 & 250,8 & $2^{\circ}$ & $01 / 03$ a 29/03 de 2010 \\
\hline$A B R$ & 30,6 & 21,4 & 26,3 & 82 & 272,8 & $3^{\circ}$ & $30 / 03$ a $28 / 04$ de 2010 \\
\hline MAIO & 31,4 & 20,6 & 26,9 & 77 & 16 & $4^{\circ}$ & $29 / 04$ a $26 / 05$ de 2010 \\
\hline \multirow[t]{2}{*}{ Total } & & & 25,2 & & 1122,80 & & \\
\hline & & \multicolumn{6}{|c|}{ Média histórica } \\
\hline JAN & 31,25 & 21,59 & 25,11 & 86 & 248,1 & & \\
\hline FEV & 30,80 & 21,69 & 25,06 & 87 & 265,3 & & \\
\hline MAR & 30,60 & 21,55 & 25,05 & 87 & 295,6 & & \\
\hline$A B R$ & 30,65 & 21,50 & 25,30 & 86 & 226 & & \\
\hline MAIO & 31,65 & 21,40 & 25,10 & 82 & 107,9 & & \\
\hline Total & & & & & 1142,9 & & \\
\hline
\end{tabular}


O solo da área experimental foi classificado como Neossolo Quartzarênico Órtico (Embrapa, 2006). Antes do estabelecimento da forrageira foi realizada a caracterização química e física do solo nas camadas de 0-20 e de 20-40 $\mathrm{cm}$ (Tabela 2).

Tabela 2. Características químicas e físicas do solo da área experimental, por ocasião da instalação do ensaio em novembro de 2009

\begin{tabular}{|c|c|c|c|c|c|c|c|c|c|c|}
\hline Camada & M.O.(1) & $\mathrm{pH}$ & $\mathrm{P}$ & $\mathrm{K}^{+}$ & $\mathrm{Ca}^{2+}$ & $\mathrm{Mg}^{2+}$ & $\mathrm{H}^{+}+\mathrm{Al}^{3+}$ & $\mathrm{SB}^{(2)}$ & $\mathrm{CTC}^{(3)}$ & $\mathrm{CTC}^{(4)}$ \\
\hline $\mathrm{Cm}$ & $g \mathrm{dm}^{-3}$ & $\mathrm{CaCl}_{2}$ & \multicolumn{2}{|c|}{---mg dm } & ---------- & $=\mathrm{mol}_{\mathrm{c}} \mathrm{d}$ & 年------ & \multicolumn{3}{|c|}{$---\mathrm{cmol}_{\mathrm{c}} \mathrm{dm}^{-3}-\mathrm{-}^{---}$} \\
\hline $0-20$ & 15,8 & 4,06 & 0,60 & 0,28 & 1,53 & 1,48 & 3,96 & 3,15 & 7,2 & 3,4 \\
\hline \multirow[t]{3}{*}{$20-40$} & 15,2 & 4,17 & 0,55 & 0,30 & 0,52 & 0,75 & 4,8 & 1,23 & 6,15 & 5,6 \\
\hline & $V^{(5)}$ & $\mathrm{m}^{(6)}$ & \multicolumn{2}{|c|}{$C E^{(7)}$} & Dens. Ap. ${ }^{(8)}$ & Areia & Silte & Argila & \multicolumn{2}{|c|}{ Clas. Text. ${ }^{(9)}$} \\
\hline & (--------- & b-------- & \multicolumn{2}{|c|}{ ds $m^{-1}$} & $\mathrm{~g} \mathrm{~cm}^{-3}$ & $\%$ & $\%$ & $\%$ & \multirow{2}{*}{\multicolumn{2}{|c|}{ Areia }} \\
\hline $0-20$ & 35,32 & 31,40 & \multirow{2}{*}{\multicolumn{2}{|c|}{$\begin{array}{l}0,07 \\
0,06\end{array}$}} & 1,55 & 94,85 & 1,90 & 3,25 & & \\
\hline $20-40$ & 41,37 & 32,36 & & & 1,53 & 93,75 & 2,75 & 3,50 & \multicolumn{2}{|c|}{ Areia } \\
\hline
\end{tabular}

Em função das características químicas do solo foi realizado o preparo da área para plantio pelo método de cultivo mínimo (uma gradagem). Independente do tratamento foi realizada a correção do solo pelo método de saturação de bases $\left(V_{2}=60 \%\right)$ e aplicado uma tonelada de calcário dolomítico (PRNT = 98\%) por hectare no pré-plantio em toda área experimental. A gramínea (capim Mombaça: valor cultural $=34 \%$ ) foi semeada a lanço em dezembro de 2009, com taxa de semeadura de $4,5 \mathrm{~kg}$ de sementes puras viáveis por hectare). No estágio de três folhas/perfilho aplicou-se 60 $\mathrm{kg} \mathrm{ha}^{-1}$ de $\mathrm{P}_{2} \mathrm{O}_{5}$ via superfosfato simples e 100 $\mathrm{kg} \mathrm{ha}^{-1}$ de $\mathrm{N}$ na forma de ureia (Collier et al., 2008), caracterizando a adubação básica de formação. Aos 40 dias após a emergência das plantas foi realizado um corte de uniformização e, posteriormente (sete dias), com a área formada, aplicou-se as doses do resíduo líquido de laticínio.

O delineamento experimental utilizado foi em blocos casualizados, com oito tratamentos e quatro repetições, totalizando 32 unidades experimentais de $9,0 \mathrm{~m}^{2}$ cada $(3,0 \times 3,0 \mathrm{~m})$, sendo a área útil da parcela de $1,0 \mathrm{~m}^{2}$.

O resíduo foi composto a partir de descartes e/ou sobras da produção de iogurte e requeijão, das águas de limpeza dos equipamentos e instalações, e de soro de leite.

Foram estudadas seis doses de resíduo líquido de laticínio (RLL), correspondente a 10 , 50, 100, 150, 200 e $400 \mathrm{~m}^{3} \mathrm{ha}^{-1}$, aplicadas nos dois primeiros ciclos de produção, e mais dois tratamentos adicionais (Oliveira et al., 2008). O primeiro tratamento adicional foi o controle (não aplicação de resíduo), o qual recebeu apenas calagem, já o segundo tratamento adicional foi caracterizado pelo processo convencional de fertilização de pastagens, com o fornecimento de NPK nas doses recomendadas por Collier et al. (2008) (Tabela 3). No terceiro e quarto ciclo foi verificado o efeito residual destas aplicações sobre o crescimento do capim, sendo que $\circ 1^{\circ}$ e $2^{\circ}$ ciclo ocorreram no período chuvoso; $03^{\circ}$ ciclo compreendeu a transição águas-seca e o $4^{\circ}$ ciclo se deu no período seco (Tabela 1).

As doses de RLL foram aplicadas de maneira uniforme, com auxílio de regador, nas parcelas. Nos tratamentos $10 \mathrm{~m}^{3} \mathrm{ha}^{-1}, 50 \mathrm{~m}^{3} \mathrm{ha}^{-1}$, $100 \mathrm{~m}^{3} \mathrm{ha}^{-1}, 150 \mathrm{~m}^{3} \mathrm{ha}^{-1}$ e $200 \mathrm{~m}^{3} \mathrm{ha}^{-1}$ de RLL foi adicionado água potável para igualar o volume de líquido fornecido pela dose de $400 \mathrm{~m}^{3} \mathrm{ha}^{-1}$ como se segue: $10 \mathrm{~m}^{3} \mathrm{ha}^{-1}$ de RLL $+390 \mathrm{~m}^{3} \mathrm{ha}^{-1}$ de $\mathrm{H}_{2} \mathrm{O} ; 50 \mathrm{~m}^{3} \mathrm{hq}^{-1}$ de RLL $+350 \mathrm{~m}^{3} \mathrm{hq}^{-1}$ de $\mathrm{H}_{2} \mathrm{O} ; 100$ $\mathrm{m}^{3} \mathrm{ha}^{-1}$ de RLL $+300 \mathrm{~m}^{3} \mathrm{ha}^{-1}$ de $\mathrm{H}_{2} \mathrm{O} ; 150 \mathrm{~m}^{3} \mathrm{ha}^{-1}$ de $\mathrm{RLL}+250 \mathrm{~m}^{3} \mathrm{ha}^{-1}$ de $\mathrm{H}_{2} \mathrm{O} ; 200 \mathrm{~m}^{3} \mathrm{ha}^{-1} \mathrm{de} \mathrm{RLL}+200$ $\mathrm{m}^{3} \mathrm{ha}^{-1}$ de $\mathrm{H}_{2} \mathrm{O}$. Aos tratamentos controle e NPK foram fornecidos $400 \mathrm{~m}^{3} \mathrm{ha}^{-1}$ de $\mathrm{H}_{2} \mathrm{O}$.

As características químicas do RLL, coletado logo após sua produção, oriundo do Laticínio Biana Ltda de Araguaína/TO, e o total dos nutrientes $\mathrm{N}, \mathrm{P}, \mathrm{K}^{+} \mathrm{e} O \mathrm{Na}^{+}$, fornecidos nas aplicações, estão apresentados nas Tabelas 3 e 4, respectivamente.

A $1^{a}$ aplicação de RLL foi realizada no $5^{\circ}$ dia após o corte de uniformização dos canteiros já formados e a $2^{a}$ aplicação ocorreu após 0 
corte do $1^{\circ}$ ciclo. $O$ manejo de corte seguiu o método de pastejo sob lotação rotacionada, com período de descanso de 28 dias e altura de corte de $30 \mathrm{~cm}$. As aplicações foram efetuadas de modo a evitar o contato direto do resíduo com o limbo foliar das plantas em função das características químicas (triglicerídeos) do resíduo, e sua possível promoção de efeitos de confundimento.

Tabela 3. Características do resíduo líquido de laticínio utilizado no experimento DBO: demanda bioquímica de oxigênio

\begin{tabular}{lccc}
\hline Parâmetros & $1^{\mathrm{a}}$ amostra & $2^{\mathrm{a}}$ amostra & Técnica \\
\hline $\mathrm{DBO}\left(\mathrm{mg} \mathrm{O}_{2} \mathrm{~L}^{-1}\right)$ & 25343,54 & 35765,19 & Titulometria \\
Nitrogênio $\left(\mathrm{mg} \mathrm{L}^{-1}\right)$ & & & \\
Amoniacal & 67,80 & 81,70 & Espectofotometria \\
Nitrato & 7,0 & 8,0 & Espectofotometria \\
Nitrito & 0,048 & 0,039 & Espectofotometria \\
Ortofosfato $\left(\mathrm{mg} \mathrm{L}^{-1}\right)$ & 178,8 & 183,0 & Espectofotometria \\
Sódio (mg L-1) & 112,94 & 107,88 & Fotometria de chama \\
Potásssio (mg L-1) & 735,29 & 715,97 & Fotometria de chama \\
Sólidos Totais $\left(\mathrm{mg} \mathrm{L}^{-1}\right)$ & 16244,4 & 14406,0 & Gravimetria \\
pH & 3,24 & 4,10 & Potenciômetro \\
\hline
\end{tabular}

Tabela 4. Total de nutrientes fornecido nas duas aplicações do resíduo líquido de laticício de acordo com as doses utilizadas e fertilização química

\begin{tabular}{ccccccccc}
\hline & \multicolumn{3}{c}{$1^{\circ}$ Ciclo } & \multicolumn{5}{c}{$2^{\circ}$ ciclo } \\
\cline { 2 - 9 } \begin{tabular}{c} 
Tratamentos \\
\cline { 2 - 9 }$\left(\mathrm{m}^{3} \mathrm{ha}^{-1}\right)$
\end{tabular} & $\mathrm{N}$ & $\mathrm{P}$ & $\mathrm{K}$ & $\mathrm{Na}$ & $\mathrm{N}$ & $\mathrm{P}$ & $\mathrm{K}$ & $\mathrm{Na}$ \\
10 & 0,7 & 1,8 & 7,34 & 1,13 & 0,8 & 1,83 & 7,14 & 1,07 \\
50 & 3,5 & 8,94 & 36,7 & 5,65 & 4,05 & 9,15 & 35,7 & 5,35 \\
100 & 7 & 17,8 & 73,56 & 11,3 & 8,1 & 18,3 & 71,5 & 10,7 \\
150 & 10,5 & 26,7 & 110,2 & 16,95 & 12,15 & 27,45 & 107,2 & 16,1 \\
200 & 14 & 35,6 & 146,9 & 22,6 & 16,2 & 36,6 & 142,9 & 21,4 \\
400 & 28 & 71,2 & 293,8 & 45,2 & 32,4 & 73,2 & 285,8 & 42,8 \\
NPK & 100 & 80 & 60 & - & 100 & 0,0 & 20 & - \\
\hline
\end{tabular}

As variáveis agronômicas avaliadas em cada ciclo foram o acúmulo de massa seca total (MST) (somatório de folhas + colmos + partes senescidas), massa seca de lâmina foliar (MSF), massa seca dos colmos + bainha foliar (MSC) e massa seca de material morto (MSMM), além da relação lâmina foliar/colmo + bainha e do índice de área foliar (IAF), obtido pelo método destrutivo e com as medições de área e pesagem de segmentos, o número de perfilhos (NP) e a altura do dossel. A forragem foi coletada na área útil sob influência dos tratamentos $\left(1,0 \mathrm{~m}^{2}\right)$, respeitando-se o intervalo de 28 dias (em função do número ótimo de folhas vivas por perfilho, de modo a evitar-se a senescência e assegurar a recuperação da planta após a desfolha). A gramínea foi colhida à altura de $30 \mathrm{~cm}$ do solo (em função da preservação do IAF crítico) e coletadas sub-amostras para determinação da sua composição morfológica. O número de perfilhos (NP) foi determinado por meio da contagem direta em uma área transversal à área útil da parcela no sentido norte-sul, com quadro de amostragem de 0,15 $\mathrm{m}^{2}(1,0 \times 0,15$ $\mathrm{m})$. Foram medidos 10 perfilhos na área útil de cada unidade experimental, sendo que a altura, em cada ponto, correspondeu à curvatura das folhas superiores em torno da régua até o solo.

As respostas agronômicas referentes às doses do RLL dentro de cada ciclo foram submetidas à ANOVA e ao teste de regressão (Y $=\beta_{0}+\beta^{\times m^{3} R L L}+$ Erro) para verificar a significância do efeito das doses de RLL sobre os atributos avaliados. A escolha da equação de regressão foi realizada com base no coeficiente de determinação, na significância da regressão e de seus coeficientes, testados ao nível de $5 \%$ de probabilidade (teste $\mathrm{F}$ ), além da significância biológica da resposta. As respostas de cada dose ao longo dos quatro ciclos foram submetidas 
à ANOVA e comparadas $\left(Y_{R L L}=\mu+\mathrm{Ciclo}_{x(1-4)}+\right.$ $\mathrm{Bloco}_{z(1-4)}+$ Erro) pelo teste de Tukey a $5 \%$ de probabilidade.

Foi analisado o contraste entre os tratamentos NPK e $200 \mathrm{~m}^{3} \mathrm{ha}^{-1}$ de RLL, e NPK e $400 \mathrm{~m}^{3} \mathrm{ha}^{-1}$ de RLL, utilizando-se o teste Dunnett a $5 \%$ de probabilidade. Esta comparação foi realizada devido ao fornecimento de $\mathrm{K}$ e $\mathrm{P}$ por estas doses, nos dois ciclos em que se procedeu a aplicação do RLL, terem extrapolado os valores destes elementos segundo a recomendação representada pelo tratamento NPK (Tabela 4).

\section{Resultados e Discussão}

Devido à existência de variáveis quantitativas (doses de resíduos) avaliadas em períodos diferentes, o efeito de cada dose do RLL ao longo dos ciclos foi avaliado isoladamente.
O efeito da aplicação do RLL foi significativo $(\mathrm{P}<0,05)$ para o acúmulo dos componentes do capim Mombaça e também houve variação significativa entre os ciclos (Tabela 5).

A aplicação sistêmica de ordem crescente de RLL no capim Mombaça promoveu acréscimo no acúmulo de massa seca total (MST), pelo incremento dos componentes lâmina foliar (MSF) e de colmos (MSC), bem como na altura das plantas (Tabela 6) nos quatro ciclos avaliados. Esses acúmulos no $1^{\circ}, 3^{\circ}$ e $4^{\circ}$ ciclo se ajustaram ao modelo linear de regressão, já que houve incrementos lineares nesses parâmetros em função das doses de RLL. Oliveira et al. (2007), aplicando resíduos orgânicos de laticínio no capim braquiarão, também obtiveram aumento da MST e atribuíram o fato a absorção dos nutrientes do resíduo pelas plantas.

Tabela 5. Análise de variância das variáveis agronômicas do capim Mombaça submetido a doses de resíduo líquido de laticínio em diferentes ciclos

\begin{tabular}{|c|c|c|c|c|c|c|c|c|c|}
\hline \multirow{2}{*}{ FV } & \multirow{2}{*}{ GL } & \multicolumn{8}{|c|}{ QUADRADO MÉDIO } \\
\hline & & MST & MSF & MSC & $\mathrm{IAF}$ & MSMM & ALT & NP & $\mathrm{F} / \mathrm{C}$ \\
\hline DR & 6 & $14677,8^{*}$ & $13143,1^{*}$ & $159,01^{*}$ & $3,10^{*}$ & $81,400 *$ & $278,5^{*}$ & $28711,5^{*}$ & $502,33^{*}$ \\
\hline Resíduo & 18 & 301,91 & 445,3 & 1,9 & 0,15 & 0,95 & 15,20 & 1379,8 & 7,64 \\
\hline $\mathrm{CV}$ & & 11,9 & 12,2 & 18,4 & 13,4 & 25,3 & 5,2 & 7 & 17,7 \\
\hline CICLOS & 3 & $31490,5^{*}$ & $4833,8^{*}$ & $10,66^{*}$ & $0,72^{*}$ & $1,90^{*}$ & $84,37^{*}$ & $178665,02 *$ & $146,56^{*}$ \\
\hline Resíduo & 9 & 593,74 & 122,6 & 0,12 & 0,04 & 5,51 & 9,13 & 1641,15 & 0,48 \\
\hline $\mathrm{CV}$ & & 11,1 & 11,8 & 18,5 & 13,4 & 30 & 4,8 & 10,3 & 15,2 \\
\hline
\end{tabular}

Tabela 6. Efeito das doses do resíduo líquido de laticínio no acúmulo de massa seca total, lâmina foliar, colmo, IAF, massa morta e altura das plantas do capim Mombaça em quatro ciclos de produção; efeito de cada nível de aplicação do resíduo ao longo dos ciclos e comparações entre as doses de 200 e $400 \mathrm{~m}^{3} \mathrm{ha}^{-1}$ com o tratamento NPK. Significativo a $5 \%$ de probabilidade pelo teste F. $a=1^{\circ}$ ciclo; $b=2^{\circ} \mathrm{ciclo} ; \mathrm{c}=3^{\circ}$ ciclo e $d=4^{\circ}$ ciclo. Ciclo $=28$ dias

\begin{tabular}{|c|c|c|c|c|c|}
\hline Ciclos & $1^{\circ}$ & $2^{\circ}$ & $3^{\circ}$ & $4^{\circ}$ & \\
\hline Tratamentos & \multicolumn{4}{|c|}{ Massa seca total $\left(\mathrm{g} \mathrm{m}^{-2}\right)$} & $\mathrm{CV}$ \\
\hline 0 & $69,3 \mathrm{bc}$ & $141,5 \mathrm{a}$ & $99,6 \mathrm{~b}$ & $57,9 \mathrm{C}$ & 17,0 \\
\hline 10 & $188,6 \mathrm{~b}$ & $247,4 a$ & $169,4 \mathrm{~b}$ & $86,4 \mathrm{C}$ & 10,7 \\
\hline 50 & $216,9 \mathrm{~b}$ & $353,9 a$ & $218,3 \mathrm{~b}$ & $127,1 \mathrm{c}$ & 6,5 \\
\hline 100 & $230,1 \mathrm{~b}$ & 443,1 a & $275,4 \mathrm{~b}$ & $207,4 \mathrm{c}$ & 14,5 \\
\hline 150 & $221,5 \mathrm{~b}$ & $497,7 \mathrm{a}$ & $272,6 \mathrm{~b}$ & $148,8 \mathrm{c}$ & 10,2 \\
\hline 200 & $233,4 \mathrm{CA}$ & $395,7 a B$ & $311 \mathrm{bB}$ & $227,7 \mathrm{CB}$ & 11,8 \\
\hline 400 & $245,4 \mathrm{bA}$ & $512,8 \mathrm{aA}$ & 444,1 aA & $288,6 \mathrm{bA}$ & 9,8 \\
\hline NPK & $195,2 \mathrm{CB}$ & 388 bB & 509 aA & $271,7 \mathrm{bA}$ & 8,4 \\
\hline$\beta 0$ & 166,1 & 211,125 & 157,7 & 93,85 & \\
\hline$\beta^{1}$ & 0,266 & 2,15 & 0,754 & 0,535 & \\
\hline$\beta^{2}$ & - & $-0,0036$ & - & - & \\
\hline$R^{2}$ & 0,37 & 0,79 & 0,89 & 0,83 & \\
\hline $\mathrm{CV}$ & 17,9 & 9,8 & 7,1 & 13,1 & \\
\hline \multicolumn{6}{|c|}{ Massa seca de lâmina foliar $\left(\mathrm{g} \mathrm{m}^{-2}\right)$} \\
\hline 0 & $56,8 \mathrm{c}$ & $121,8 \mathrm{a}$ & $87,2 \mathrm{~b}$ & $43,7 \mathrm{~d}$ & 14,5 \\
\hline 10 & $177,9 \mathrm{~b}$ & $216,9 \mathrm{a}$ & $138,9 \mathrm{c}$ & $64,6 \mathrm{~d}$ & 9,5 \\
\hline 50 & $202,2 \mathrm{~b}$ & 311,9 a & $187,6 \mathrm{~b}$ & $99 \mathrm{c}$ & 9,9 \\
\hline 100 & $211,7 \mathrm{~b}$ & $365,2 a$ & $250,5 \mathrm{~b}$ & $159,1 \mathrm{C}$ & 9,4 \\
\hline
\end{tabular}


Produção e Saúde Animal

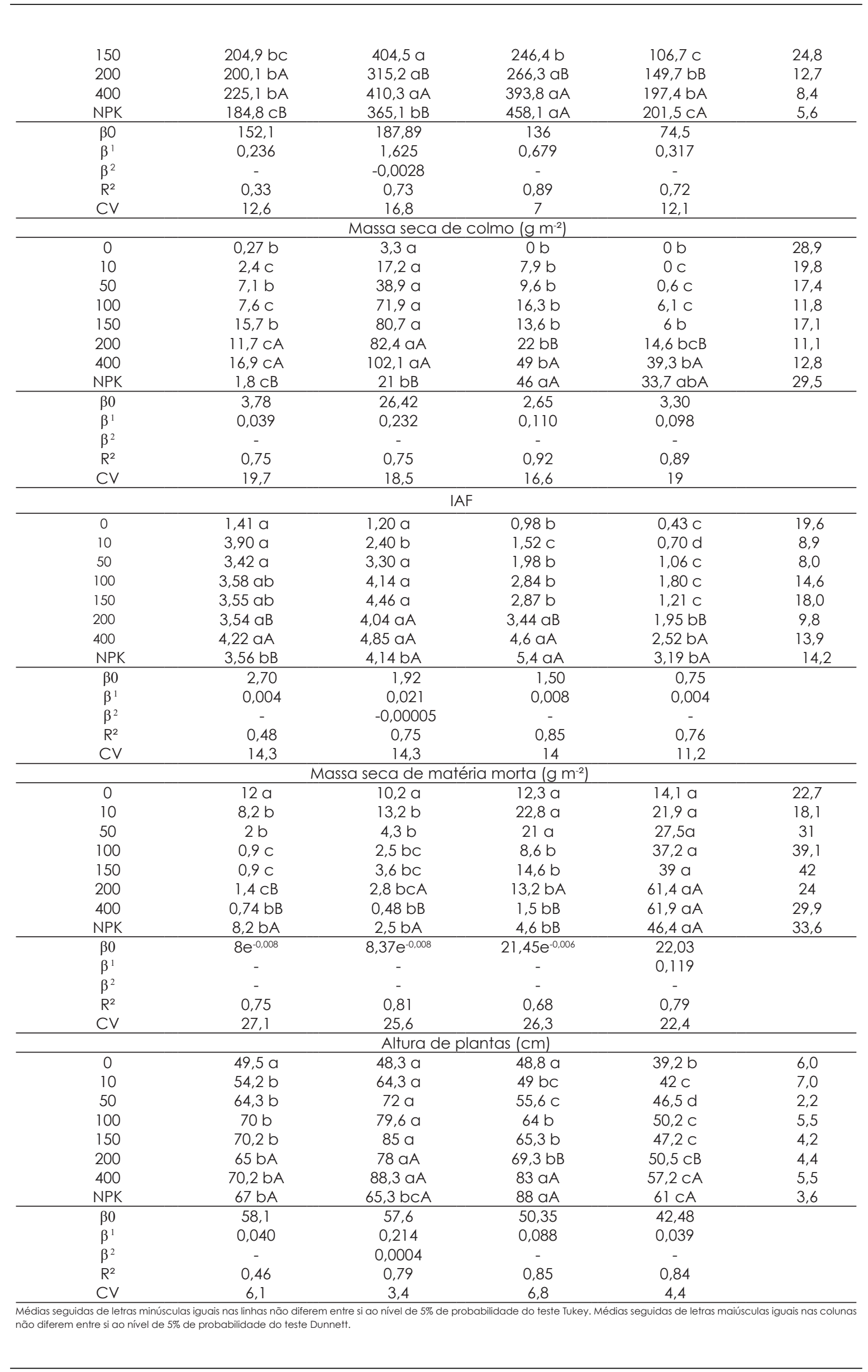


Somente no $2^{\circ}$ ciclo a MST, a MSF, O IAF e altura das plantas (Tabela 6) apresentaram respostas ajustadas ao modelo quadrático de regressão, tendo no ponto máximo da curva a dose de $290 \mathrm{~m}^{3} \mathrm{ha}^{-1}$ de RLL. Esta resposta pode ter ocorrido devido à saturação no solo dos elementos limitantes no $1^{\circ}$ ciclo com a segunda aplicação do RLL. Assim, a dose de $400 \mathrm{~m}^{3} \mathrm{ha}^{-1}$ no $2^{\circ}$ ciclo pode ter aumentado o estoque de $\mathrm{P}$ e $\mathrm{K}^{+}$no solo, não contribuindo mais para o desenvolvimento da planta.

Gheri et al. (2003) também observaram que uma segunda aplicação de $300 \mathrm{~kg} \mathrm{ha}^{-1}$ de $\mathrm{K}_{2} \mathrm{O}$ via soro de leite reduziu o acúmulo de massa seca do capim Tanzânia (Panicum maximum Jaca. cv. Tanzânia) atribuindo o resultado ao desequilíbrio nutricional e a deficiência de $\mathrm{Mg}$ do soro, já que observaram concentrações deste elemento no solo de $0,2 \mathrm{cmol}_{\mathrm{c}} \mathrm{dm}^{-3}$, enquanto neste estudo, a concentração de $\mathrm{Mg}$ no solo, sob a maior dose de RLL, foi de $0,6 \mathrm{cmol}_{c}$ $\mathrm{dm}^{-3}$. Oliveira et al. (2008) aplicando resíduo de curtume no capim elefante observaram resposta quadrática com o aumento das doses e atribuíram o fato ao desbalanço nutricional ou efeitos tóxicos do resíduo.

No $2^{\circ}$ ciclo, o ajuste da MSF ao modelo quadrático (Tabela 6) também ocorreu devido a menor participação deste componente na MST das plantas sob as maiores doses de RLL. A menor proporção de LF nas maiores doses d resíduo (Tabela 6), neste ciclo, ocorreu devido as modificações na partição de fotossintatos em favor do componente colmo (Alexandrino et al., 2005) em função do IAF crítico (ponto em que 95\% da radiação fotossinteticamente ativa é interceptada pelo dossel forrageiro).

As respostas de incrementos da MST, MSF, IAF e altura das plantas no $3^{\circ}$ e $4^{\circ}$ ciclos (Tabela 6) se devem ao efeito residual do RLL. Mesmo com o encerramento das chuvas em meados do $3^{\circ}$ ciclo, o crescimento do capim ainda ocorreu, mesmo com menor intensidade, sob as maiores doses de RLL, no $4^{\circ}$ ciclo. Oliveira et al. (2007) também relataram haver efeito residual de doses de resíduos de laticínio no desempenho de gramíneas.

A dose $400 \mathrm{~m}^{3} \mathrm{ha}^{-1}$ de RLL promoveu o maior acúmulo de MSF nos ciclos de produção (Tabela 6). Este acúmulo de MST, sem o aumento do número de perfilhos, fato verificado até o $2^{\circ}$ ciclo, de acordo com Gomide et al. (2003), pode ser traduzido em maior comprimento de LF e/ou maior número de folhas vivas por perfilho, aumentando seu peso médio.

O intervalo de corte estabelecido (28 dias) promoveu, no $2^{\circ}$ e no $3^{\circ}$ ciclo, nas plantas sob as maiores doses, altura satisfatória para o início do momento de pastejo, o qual é recomenda em torno de $80 \mathrm{~cm}$ para o capim Mombaça (Fulkerson et al., 1999) (Tabela 6).

$O$ incremento do IAF se deu de forma similar ao da MSF nos quatro ciclos produtivos (Tabela 6), tendo o fornecimento do RLL elevado os valores de IAF. No $4^{\circ}$ ciclo (seca), o incremento do IAF sob as maiores doses de RLL ocorreu, possivelmente, pela melhor nutrição das plantas, principalmente em relação ao $\mathrm{K}^{+}$que atua como regulador osmótico (Alexandrino et al., 2005).

$O$ incremento da MSC (Tabela 6) foi afetado positivamente pela aplicação do RLL e ajustaram-se, em todos os quatro ciclos, ao modelo linear de regressão. $O$ aporte de nutrientes fornecido pelo resíduo contribuiu para aumentar o acúmulo de MSF e o sombreamento na base das touceiras que desencadeou os processos de alongamento de colmo (Gomide et al., 2003).

A massa seca de matéria morta (MSMM) diminuiu com o aumento das doses do RLL em todos os ciclos (Tabela 6). Isto pode ter ocorrido devido ao aumento da condição nutricional da planta, da diminuição da translocação de nutrientes e do alongamento de colmos. Do $1^{\circ}$ ao $3^{\circ}$ ciclo, os resultados se ajustaram ao modelo exponencial de regressão, já que o aumento das doses de RLL promoveu diminuição da morte de folhas (MSMM).

As respostas de MST, MSF, MSC e altura das plantas em função das doses de RLL, ao longo do período experimental, revelaram que as plantas apresentaram menor desempenho no $1^{\circ}$ ciclo e aumentaram o acúmulo de massa no $2^{\circ}$ ciclo (Tabela 6).

O tratamento controle apresentou crescimento (Altura e MST) semelhante do $1^{\circ}$ ao $3^{\circ}$ ciclo, diminuindo no $4^{\circ}$ ciclo (Tabela 
6). Estas respostas podem ser atribuídas ao baixo desenvolvimento das plantas no período favorável $\left(1^{\circ}\right.$ ao $3^{\circ}$ ciclo) devido a baixa disponibilidade de nutrientes no solo, que pode ter causado deficiências nas plantas, e a seca no $4^{\circ}$ ciclo, que causou estresse hídrico associado às possíveis carências.

No $3^{\circ}$ ciclo, o acúmulo de MST e a altura diminuíram em relação ao $2^{\circ}$ ciclo para todas as doses de RLL. $O 4^{\circ}$ ciclo apresentou as menores alturas e os menores acúmulos de MST de todo período, exceto para as doses de 200 e 400 $\mathrm{m}^{3} \mathrm{ha}^{-1}$ de RLL (Tabela 6). Logo, as quantidades de nutrientes fornecidos até a dose de $150 \mathrm{~m}^{3} \mathrm{ha}$ ', aparentemente, não aumentaram as reservas das plantas ou sua capacidade exploratória, permitindo a diminuição do vigor de rebrota na época seca.

Para o IAF, as doses até $150 \mathrm{~m}^{3} \mathrm{ha}^{-1}$ de RLL foram semelhantes no $1^{\circ}$ e $2^{\circ}$ ciclos, diminuindo no $3^{\circ}$ e no $4^{\circ}$ ciclo. Sob as maiores doses de RLL, as médias de IAF se mantiveram iguais até $\circ 3^{\circ}$ ciclo e diminuíram somente no $4^{\circ}$ ciclo (Tabela 6). Estas respostas indicam a melhor condição das plantas, reflexo da maior taxa de acúmulo e menor senescência das plantas.

O acúmulo de MSMM aumentou do $1^{\circ}$ para o $4^{\circ}$ ciclo em função de todas as doses de RLL (Tabela 6), apesar da diminuição da MST do $2^{\circ}$ para $\circ 4^{\circ}$ ciclo. Logo as proporções de MSMM na
MST sob cada dose de RLL foram distintas (Tabela 6). Para a não aplicação do RLL (tratamento controle), as plantas apresentaram os mesmos valores de MSMM nos quatro ciclos produtivos, devido à menor utilização da translocação de nutrientes, e menor gasto de mantença por sua menor biomassa (Gomide et al., 2003).

O perfilhamento em função das doses de RLL e no tratamento NPK, ao longo dos ciclos, aumentou do $1^{\circ}$ para $\circ 3^{\circ}$ ciclo e se manteve no $4^{\circ}$ ciclo nas doses de 100 a $400 \mathrm{~m}^{3} \mathrm{ha}^{-1}$ de RLL. Nas doses de 10 e de $50 \mathrm{~m}^{3} \mathrm{ha}^{-1}$, o NP do $4^{\circ}$ ciclo diminuiu em relação ao $3^{\circ}$ ciclo, possivelmente porque o efeito residual do RLL não chegou a existir neste ciclo e estas plantas se encontravam sob deficiência hídrica e nutricional, com consequente morte de perfilhos (Melo et al., 2009) (Tabela 7).

No tratamento controle o perfilhamento aumentou do $1^{\circ}$ para $\circ 2^{\circ}$ ciclo (Tabela 7). Este número se manteve do $2^{\circ}$ ao $4^{\circ}$ ciclo devido à baixa formação e renovação de tecido destas plantas que possivelmente se achavam deficientes nutricionalmente.

O tratamento adicional NPK, quando comparado às doses de 200 e $400 \mathrm{~m}^{3} \mathrm{ha}^{-1}$ de RLL (Tabela 7), apresentou número de perfilhos semelhante à dose de $400 \mathrm{~m}^{3} \mathrm{ha}^{-1}$ de RLL no $1^{\circ}, 3^{\circ}$ e no $4^{\circ}$ ciclo, demonstrando a maior eficiência da maior dose do resíduo.

Tabela 7. Efeito do resíduo líquido de laticínio e ciclo de produção sob o número de perfilhos do capim Mombaça.

\begin{tabular}{|c|c|c|c|c|c|}
\hline Ciclos & $1^{\circ}$ & $2^{\circ}$ & $3^{\circ}$ & $4^{\circ}$ & \\
\hline Tratamentos & \multicolumn{4}{|c|}{ Número de perfilhos $\mathrm{m}^{2}$} & $\mathrm{CV}$ \\
\hline 0 & $183,3 \mathrm{~b}$ & 351,1 a & $375 a$ & 388,3 a & 5,8 \\
\hline 10 & $255,5 \mathrm{~b}$ & 340 a & 526 a & 388 b & 16,8 \\
\hline 50 & $244,4 \mathrm{C}$ & $353,3 \mathrm{c}$ & 584,4 a & $528,3 \mathrm{~b}$ & 3,8 \\
\hline 100 & $337,7 \mathrm{~b}$ & $375,5 b$ & 591,1 a & $615 a$ & 9,7 \\
\hline 150 & $311,1 \mathrm{~b}$ & $340 \mathrm{~b}$ & $562,2 \mathrm{a}$ & 543,3 a & 8,4 \\
\hline 200 & $242,2 \mathrm{CB}$ & $344,4 \mathrm{bB}$ & $584,4 \mathrm{aB}$ & $633,3 \mathrm{aB}$ & 6 \\
\hline 400 & $295,5 \mathrm{bA}$ & $362,2 \mathrm{bB}$ & 682,3 aA & $710 \mathrm{aA}$ & 7,9 \\
\hline NPK & $333,3 \mathrm{bA}$ & $468,9 \mathrm{bA}$ & 753,3 aA & $755,5 \mathrm{abA}$ & 23,8 \\
\hline$\beta 0$ & 269,4 & 349,3 & 498,3 & 421,5 & \\
\hline$\beta^{1}$ & Ns & Ns & 0,410 & 0,835 & \\
\hline $\mathrm{R}^{2}$ & - & - & 0,38 & 0,77 & \\
\hline CV & - & - & 7,3 & 6,7 & \\
\hline
\end{tabular}

A relação Folha/Colmo (F/C) das plantas foi alterada com o fornecimento do RLL, de modo a aumentar a proporção das hastes com o aumento das doses de RLL nos quatro ciclos avaliados (Tabela 8) Os dados de F/C se ajustaram ao modelo exponencial da regressão, devido ao incremento cada vez menor com a aplicação de doses cada vez maiores. Silva 
Neto et al. (2010) também observaram que o aumento do fornecimento de nutrientes via resíduo líquido de frigorífico reduz a relação F/C.

O tratamento controle no $1^{\circ}, 3^{\circ}$ e $4^{\circ}$ ciclo e as doses de 10 e $50 \mathrm{~m}^{3} \mathrm{ha}^{-1}$ de RLL no $4^{\circ}$ ciclo não apresentaram material a ser colhido para quantificar MSC (Tabela 8). Logo, foram representadas no ponto 100, referido a $100 \%$ de LF no material obtido, estas respostas dão ideia da menor taxa de crescimento dessas plantas. Estes resultados concordam com os de Quadros et al. (2002) que verificaram que o menor fornecimento de nutriente às cultivares de Panicum-spp. promoveu maior relação $F / C$, enquanto que o aumento da adubação favoreceu o incremento de MSC e a diminuição da relação $\mathrm{F} / \mathrm{C}$.

Devido ao maior fornecimento de $\mathrm{K}^{+}$ pelo RLL (Tabela 4), elementos como P poderiam limitar o desempenho das plantas, já que Ali et al. (2006) estipularam um fornecimento mínimo de $330 \mathrm{~m}^{3} \mathrm{ha}^{-1}$ de resíduo de leite para fornecer $30 \mathrm{~kg}$ $\mathrm{P}_{2} \mathrm{O}_{5}$. Deste modo, a aplicação de $75 \%(60 \mathrm{~kg} \mathrm{ha}$ 1) da dose recomendada de fósforo, assegurou, sob a maior dose do RLL, desempenho similar ao da adubação convencional, promovendo maiores IAFs e diminuindo a F/C. Isto ainda demonstrou a capacidade do RLL fornecer fósforo ao sistema solo planta.

A aplicação do RLL favoreceu a diminuição da relação F/C (Tabela 8), a qual foi menor no $2^{\circ}$ e no $3^{\circ}$ ciclo, onde a proporção de MSC foi aumentada (Tabela 7). Já no $1^{\circ}$ e no $4^{\circ}$ ciclo, devido às menores taxas de crescimentos (Tabela 6) das plantas sob todos as doses de aplicação do RLL, a proporção de MSC no material colhido foi menor e a relação $F / C$ foi maior. A diminuição da MSC no $4^{\circ}$ ciclo pode ter ocorrido em função do efeito dos cortes do $2^{\circ} \mathrm{e}$ no $3^{\circ}$ ciclo, sendo que a MSC observada no $4^{\circ}$ ciclo advém de perfilhos surgidos neste ciclo de modo a aumentar a relação F/C (Alexandrino et al., 2003). A diminuição da relação $F / C$ do $1^{\circ}$ para $\circ 2^{\circ}$ ciclo ocorreu devido ao aumento da MSC, já que os perfilhos do $2^{\circ}$ ciclo eram, na grande maioria, os mesmos remanescentes do $1^{\circ}$ ciclo, tendo 56 dias de vida e não sofrido decapitação do meristema no primeiro corte.

O tratamento controle somente apresentou MSC no $2^{\circ}$ ciclo, devido a melhor condição de crescimento neste ciclo e ao acúmulo das hastes do $1^{\circ}$ para $\circ 2^{\circ}$ ciclo. No $3^{\circ}$ e $4^{\circ}$ ciclos não houve incremento de hastes, devido ao definhamento das plantas.

Tabela 8. Relação Folha/Colmo do capim Mombaça em função das doses do resíduo líquido de laticínio ao longo de quatro ciclos produtivos

\begin{tabular}{|c|c|c|c|c|c|}
\hline Ciclos & $1^{\circ}$ & $2^{\circ}$ & $3^{\circ}$ & $4^{\circ}$ & \\
\hline Tratamentos & \multicolumn{4}{|c|}{ Relação Folha:Colmo } & CV \\
\hline 0 & $100,0 a$ & $34,9 \mathrm{~b}$ & 100,0 a & 100,0 a & 10,1 \\
\hline 10 & $74,0 \mathrm{~b}$ & $12,7 \mathrm{~d}$ & $25,8 \mathrm{c}$ & $100,0 a$ & 9,2 \\
\hline 50 & $28,8 \mathrm{~b}$ & $8,0 \mathrm{c}$ & $21,0 \mathrm{~b}$ & 100,0 a & 11,1 \\
\hline 100 & $29,5 \mathrm{a}$ & $5,1 \mathrm{~b}$ & $15,7 \mathrm{~b}$ & $28,8 a$ & 33,7 \\
\hline 150 & $12,9 a$ & $4,9 \mathrm{~b}$ & $18,8 a$ & 18,6 a & 25,16 \\
\hline 200 & $17,1 \mathrm{aB}$ & $3,8 \mathrm{CB}$ & $8,6 \mathrm{CA}$ & $10,2 \mathrm{bA}$ & 15,4 \\
\hline 400 & $13,3 \mathrm{aB}$ & $4,, 0 \mathrm{CB}$ & $8,8 \mathrm{cA}$ & $8,0 \mathrm{bA}$ & 8,3 \\
\hline NPK & $97,0 \mathrm{aA}$ & $12,7 \mathrm{bA}$ & $10,0 \mathrm{bA}$ & $6,9 \mathrm{bA}$ & 9,0 \\
\hline Equação & $51,6 \mathrm{e}^{-0,0025}$ & $12,74 e^{-0,004}$ & $35,18 e^{-0,005}$ & $90,16 e^{-0,006}$ & \\
\hline$R^{2}$ & 0,61 & 0,62 & 0,55 & 0,87 & \\
\hline $\mathrm{CV}$ & 19,4 & 26,5 & 16,6 & 8,3 & \\
\hline
\end{tabular}

O tratamento adicional NPK, quando comparado com os níveis de 200 e $400 \mathrm{~m}^{3} \mathrm{ha}^{-1}$ de RLL (Tabelas 6, 7 e 8), apresentou no $1^{\circ}$ e $2^{\circ}$ ciclo desempenho inferior a dose de $400 \mathrm{~m}^{3} \mathrm{ha}$ 1 do RLL, possivelmente devido a ocorrência de chuvas imediatamente após a aplicação de ureia, com consequente perda de $\mathrm{N}$ no $1^{\circ}$ ciclo.
Cantarela (2007) afirmou que chuvas podem provocar perda de $\mathrm{N}$ e diminuição da absorção de P. Somente no $3^{\circ}$ e no $4^{\circ}$ ciclo as respostas produtivas se igualaram a dose de $400 \mathrm{~m}^{3} \mathrm{ha}^{-1}$ de RLL. Isto demonstra haver efeito residual no período seco das adubações na época das chuvas e desempenho da dose de $400 \mathrm{~m}^{3} \mathrm{ha}^{-1}$ de 
RLL similar a adubação química. O tratamento controle apresentou os menores desempenhos em todos os ciclos, indicando que a calagem não mantém a sustentabilidade no sistema intensivo de produção (Collier, 2008).

\section{Conclusões}

A aplicação de $400 \mathrm{~m}^{3} \mathrm{ha}^{-1}$ de resíduo líquido de laticínio garantiu produções satisfatórias de massa de forragem, substituindo $25 \%$ e $100 \%$ das adubações fosfatada e potássica, respectivamente. O resíduo líquido de laticínio possui efeito residual, o qual mantém a produtividade semelhante ao efeito residual da adubação química.

\section{Referências}

Alexandrino, E.; Nascimento Júnior, D.; Regazzi, A.J.; Mosquin, P. R.; Rocha, F.C.; Sousa, D.P. 2003. Produção de massa seca e vigor de rebrotação da Brachiaria brizantha cv. Marandu submetida a diferentes doses de nitrogênio e frequências de cortes. Brazilian Journal of Veterinary Research and Animal Science 40:141-147

Alexandrino, E.; Gomide, J.A. Oliveira, J.A.; Teixeira, A.C.B.; Lanza, D.C.F. 2005. Distribuição de fotoassimilados em plantas de Panicum maximum cv. Mombaça, Revista Brasileira de Zootecnia 34:1449-1455.

Ali, I.; Morin, S.; Barrington, S.; Whalen, J.; Bonnell, R.; Martinez, J. 2006. Surface irrigation of dairy farm effluent, part I: nutrient and bacterial load. Biosystems Engineering 4:547-556.

Cammarota, M.C; Freire, D.M.G. 2006. A review on hydrolytic enzymes in the treatment of wastewater with high oil and grease content. Bioresource Technology, 23:1591-1595.

Cantarela, H. 2007. Perdas de nitrogênio. In: Novais, F.; Alvarez, V.H.; Barros, N.F.; Fontes, R.L.F.; Cantarutti, R.B.; Neves, J.C.L. (ed.). Fertilidade do solo. Sociedade Brasileira de Ciência do Solo. Viçosa-MG, Brasil. p. 414.

Collier, L.S.; Lara, M.A.S.; Vilela, L.; Siqueira, F.L.T. 2008. Recomendação de adubação e calagem a partir do manejo da fertilidade de solos cultivados com pastagens no Cerrado. In: Santos, A.C. (ed.). Manejo de solos sob pastagens Tropicais. Gráfica Ed. Impacto. Araguaína-TO, Brasil. p.16.

Empresa Brasileira de Pesquisa Agropecuária Embrapa. 2006. Centro Nacional de Pesquisa em Solos. Sistemas brasileiro de classificação de solos, Embrapa Solos $2^{\circ}$ Ed., Brasília-DF, Brasil. p. 306.
Fulkerson, W.J.; Slack, K.; Havilah, E. 1999. The effect of defoliation interval and height on growth and herbage quality of kikuyu grass (Pennisetum clandestinum). Tropical Grassland 33:138-145.

Gheri, E.O.; Ferreira, M.E.; Da Cruz, M.C.P. 2003. Resposta do capim tanzânia a aplicação de soro ácido de leite. Pesquisa Agropecuária Brasileira 38:753-760.

Gomide, C.A.M.; Gomide, J.A.; Alexandrino, E. 2003. Índices morfogênicos e de crescimento durante o estabelecimento e a rebrotação do capim Mombaça (Panicum maximum Jacq.). Revista Brasileira de Zootecnia 32:795-803.

Köppen, W. 1938. Das Geographic system der klimate. Handbuch der Klimatologie. Berlim: Bortraeger p. 603-607.

Mcdowell, R.W.; Koopmars, G.F. 2006. Assessing the bioavailability of dissolved organic phosphorus in pasture and cultivated soils treated with different rater of nitrogen fertilizer. Soil Biology Biochemistry 38:61-70.

Melo, J.C.; Santos, A.C.; Almeida, J.A.; Morais Neto, L.R. 2009. Desenvolvimento e produtividade dos capins Mombaça e Marandu cultivados em dois solos típicos do Tocantins, com diferentes regimes hídricos. Revista Brasileira de Saúde Produção Animal 10:786-800.

Oliveira, D.Q.L.; Carvalho, K.T.G.; Bastos, A.R.R.; Oliveira, L.C.A.; Marques, J.J.G.S.M.; Nascimento, R.S.M.P. 2008. Utilização de resíduos da indústria de couro como fonte nitrogenada para o capim-elefante. Revista Brasileira de Ciência do Solo 32:417-424.

Oliveira, T.A.; Lázari, T.M.; Drumond Neto, A.P.; Camelo, G.N.; Boechat, S.L.; Boechat, C.L.; Silva, M.B.; Santos, J.B.; Costa, A.S.V. 2007, Avaliação do resíduo orgânico da fábrica de laticínios em diferentes granulometrias no desenvolvimento da Braquiaria brizantha. In: Congresso Brasileiro de Ciência do Solo Gramado-RS, Brasil. Anais... SBCS - CD ROOM.

Öborn, I.; Andrist-Rangel, Y.; Askegaard, M.; Grant, C.A., Watson, C.A.; Edwards A.C. 2005. Critical aspects of potassium management in agricultural systems. Soil Use Management 21:102-112.

Quadros, D.G.; Rodrigues, L.R.A.; Favorett, V. 2002. Componentes da produção de forragem em pastagens dos capins Tanzânia e Mombaça adubados com quatro doses de NPK. Revista Brasileira de Zootecnia 31:1333-1342.

Silva Neto, S.P.; Silva, J.E.C.; Santos, A.C.; Diaz Castro, J.G.; Dim, V.P. Araújo A.S. 2010. Características agronômicas e nutricionais do capim-Marandu em função da aplicação de 
Santos et al. (2016) / Resíduo líquido de laticínio como...

resíduo líquido de frigorífico. Acta Scientiarum

Animal Sciences 32:9-17.

Tisdale, S.L.; Havlin, J.L.; Beaton, J.D.; Nelson, W.L.

1999. Soil fertility and fertilizers. An introduction to nutrient management. Prentice-Hall, Upper Saddle River, New Jersey, 6th ed, 499 p. 